\title{
Probing Ionomer Interactions with Electrocatalyst Particles in Solution
}

\author{
Sarah A. Berlinger ${ }^{1,2}$, Bryan D. McCloskey ${ }^{1,2}$, Adam Z. Weber ${ }^{2,}{ }^{*}$ \\ ${ }^{1}$ Department of Chemical and Biomolecular Engineering, University of California, Berkeley, Berkeley, CA 94720 \\ ${ }^{2}$ Energy Technologies Area, Lawrence Berkeley National Laboratory, Berkeley, CA 94720
}

\begin{abstract}
The interaction between ionomer (ion-conducting polymer) and catalyst particles in porous electrodes of electrochemical energy-conversion devices is a critical yet poorly understood phenomenon that controls device performance. This interaction stems from that in the electrode precursor inks, which also governs porous-electrode morphology during formation. In this letter, we probe the origin of this interaction in solution to unravel the ionomer/particle agglomeration process. Quartz-crystal microbalance studies detail ionomer adsorption (with a range of charge densities) to model surfaces under a variety of solvent environments, and isothermal-titration-calorimetry experiments extract thermodynamic binding information to platinum- and carbon-black nanoparticles. Results reveal that under the conditions tested, ionomer binding to platinum is similar to carbon, suggesting that adsorption to platinum-on-carbon catalyst particles in inks is likely dictated mostly by hydrophobic interactions with the carbon surface. Furthermore, water-rich solvents (relative to propanol) promote ionomer adsorption. Finally, ionomer dispersions change with time, yielding dynamic binding interactions.
\end{abstract}

The world is increasing focused on next-generation energy-conversion devices (e.g., fuel cells, $\mathrm{CO}_{2}$ and water electrolyzers, etc.) that curtail greenhouse-gas emissions and enable a renewable, electrified economy. Key in these technologies are their catalyst layers (CLs): complex porous electrodes comprised of ion-conducting polymer (ionomer) and catalyst particle agglomerates. ${ }^{1} \mathrm{CLs}$ are manufactured through solution-processing techniques involving casting/drying an ink ${ }^{2}$ : a colloidal dispersion of particles (typically platinum-on-carbon in electrolyzer anodes or fuel cells), ionomer, and mixed solvents. The most commonly used ionomer is perfluorosulfonic acid (PFSA, structure shown in Figure S1 in the Supporting Information, SI), which has a polytetrafluoroethylene backbone and sulfonic-acid group terminated sidechains. The sidechain spacing defines the equivalent weight ( $\mathrm{EW}, \mathrm{g}$ polymer/mol $\mathrm{SO}_{3}{ }^{-}$). ${ }^{3}$ Many studies have characterized dried CLs to understand structure-property-performance relationships. However, little is known about how to direct specific structures during manufacture, which to date has been primarily empirical and thus non predictive. Enabling next-generation CLs and designing them a priori necessitates understanding the forces controlling formation and structure, especially the ionomer/particle interaction. ${ }^{4}$

Solvent identity is a critical parameter that impacts ink properties and CL microstructure. The contrasting hydrophobic backbone and hydrophilic sidechains of PFSA have competing preferences in solution, and changing solvent type (including the water:propanol ratio, two common ink solvents) causes PFSA to adopt conformations that reflect this. $^{5-14}$ These different conformations affect the self-assembly of ionomer aggregates and the properties of their films post-drying. ${ }^{15-16}$ Furthermore, different conformations will alter how the ionomer adsorbs to catalyst particles. Changing the water:propanol ratio affects the acidity of dispersions, impacting electrostatic interactions between the ionomer and particles. ${ }^{13}$ Atomistic MD simulations reveal that both solvent and EW control ionomer adsorption to model carbon surfaces. ${ }^{17}$ Additionally, there seems to be a hydrophobic interaction between the ionomer backbone and the carbon surface. The impact of solvent $^{13,18-21}$ and particle type ${ }^{22-23}$ on ink aggregation is attributed to differences in ionomer/particle interactions, which propagate to impact device performance $20,24-32$ : ionomer coverage and electrochemical performance of the $\mathrm{CL}$ are dependent on the ink water:propanol ratio ${ }^{32}$. Clearly, ionomer/particle agglomerates are impacted by the interactions between these components in solution. However, decoupling particle type, solvent, and EW influences on ionomer adsorption behavior remains a challenge.

In short, CL performance depends greatly on the ionomer/particle interaction. Despite the various previous investigations, fundamental questions remain regarding the specifics of this ink interaction: what is the mechanism for ionomer adsorption to particles? Does the ionomer preferentially interact with certain materials rather than others? 
How does the presence of different solvents alter this interaction? Answering these questions is vital toward understanding $\mathrm{CL}$ inks and eventual control of $\mathrm{CL}$ structure and performance. In this letter, we explore these interplays by systematically measuring adsorption to model surfaces (to understand the impact of platinum and surface hydrophobicity) with quartz-crystal microbalance (QCM) to screen adsorption as a function of solvent (water and $n$-propanol), $\mathrm{EW}$, and surface type. For the majority of this study, we use 3M PFSA as a model ionomer due to the range of EWs available. To complement the QCM adsorption screening, we ascertain quantitative thermodynamic binding information (binding strength and mechanism) using isothermal titration calorimetry (ITC) on carbon and Pt nanoparticles. We conclude by discussing how other important parameters, including dispersion age and sidechain chemistry alter binding behavior.

Adsorption Screening. Different solvents impact how the ionomer interacts with the catalyst particles and how these ionomer/particle aggregates interact with each other. In most ink-level studies, these two effects are extremely difficult to decouple. QCM is uniquely suited to study the ionomer/particle interaction: by holding the surface constant, thereby removing the impact of solvent on particle aggregation, one can systematically investigate the impact of solvent on ionomer adsorption to a surface. The most common surfaces found in these classes of electrocatalyst nanoparticles are platinum and carbon. Therefore, we use model platinum and functionalized-gold QCM surfaces to probe the ionomer/platinum and ionomer/substrate interactions across a range of different substrate hydrophobicities (a key parameter for carbon supports): hydrophobic (alkane-thiol self-assembled monolayers, SAMs) and hydrophilic (hydroxyl- and carboxyl-terminated SAMs) functionalized gold, as well as pristine gold and platinum surfaces. The water contact angles for these surfaces increase according to alkane>carboxyl>gold >hydroxyl>platinum (Figure S2/Table S1). For each surface studied, the ionomer EW $\left(620,825\right.$, or $\left.1000 \mathrm{~g} / \mathrm{mol} \mathrm{SO}_{3}{ }^{-}\right)$and the solvent are varied, creating a substrate/EW/solvent parameter matrix (shown in Table S1). Although the planar QCM geometry differs from the spherical aspect ratio of nanoparticles, these results elucidate the relative importance of each parameter on PFSA adsorption from solution. Experimental details of functionalization and data analysis (including frequencysignal-to-mass transformation) are reported in the SI. By looking at the raw data, one can determine that ionomer adsorption to these surfaces is reversible (an example is shown in Figure S3), and that adsorption kinetics for all tested conditions proceed at the same rate (Figure S5).

To explore the effect of solvent, the two EW (620 and 1000 ) and substrate (in terms of contact angle: alkane-thiol and platinum) extremes are used. Higher EWs indicate relatively fewer sidechains per gram of polymer, or greater sidechain spacing (more backbone tetrafluoroethylene groups). 3M 1000 has the maximum spacing (equal to Nafion explored later) of the ionomers studied. The ionomers are dispersed in various water:n-propanol ratios. The frequency change of the quartz crystal due to ionomer adsorption in solvent, relative to the frequency of the crystal in pure solvent, and the associated adsorbed polymer mass is plotted in Figure 1.

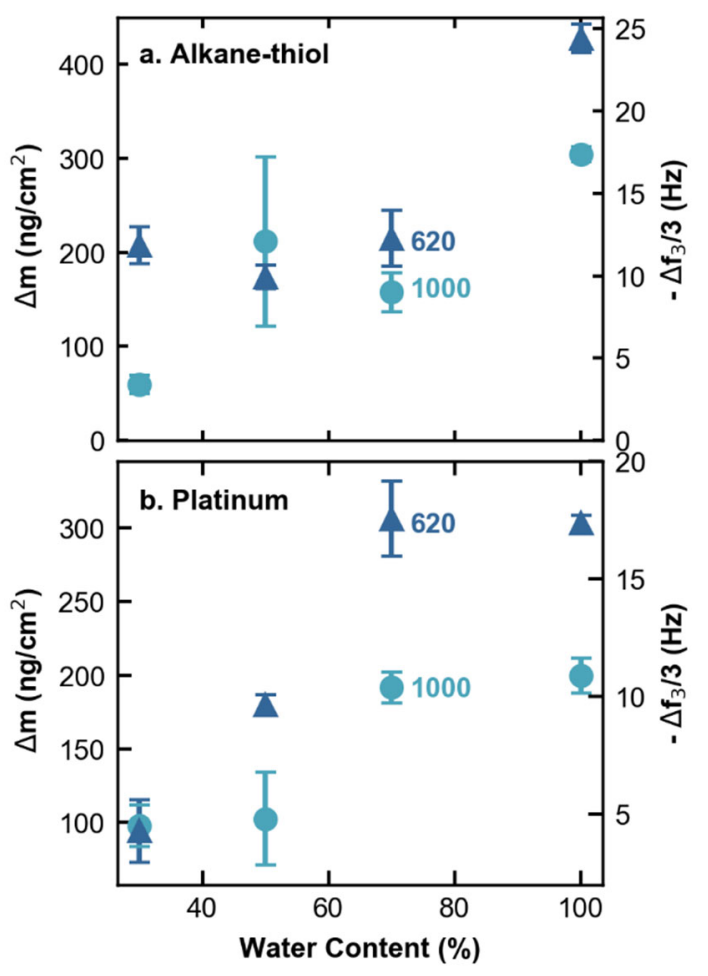

Figure 1. Frequency change $(\Delta f)$ measured at the third overtone and associated mass change $(\Delta \mathrm{m})$ due to ionomer adsorption in solution (as compared with pure solvent) on (a.) alkane-thiol and (b.) platinum model surfaces, respectively, for ionomers with EWs of 620 and $1000 \mathrm{~g} / \mathrm{mol} \mathrm{SO}_{3}{ }^{-}$dispersed in a range of water:n-propanol ratios, reported as weight percentage water.

Adsorption depends strongly on EW and solvent, in agreement with $\mathrm{MD}$ simulations. ${ }^{17}$ For all cases, more ionomer adsorbs as water content increases, likely driven by hydrophobic interactions. When comparing the $30 \%$ watercontent results to the $>80 \%$ water-content, $3 \mathrm{M} 1000$ adsorbs roughly $200 \%$ more onto platinum surfaces and $3 \mathrm{M}$ 620 adsorbs about $300 \%$ more. These values correspond to $\sim 20 \%$ coverage on the crystal at low-water contents to near-complete coverage at high-water contents (coverage estimates discussed in the $\mathrm{SI}$ ). A similar trend has been observed by AFM studies: more ionomer aggregates adsorb on platinum at higher water concentrations. ${ }^{33}$ These differences are significant and dictate the amount of ionomer strongly interacting with catalyst surfaces versus free in solution, the latter of which likely leads to large ionomer agglomerates upon drying and CL formation. Therefore, tuning the water:alcohol ratio directs how much ionomer adsorbs to particles, thereby controlling CL morphology/performance ${ }^{32,34}$.

Figure 2 examines the relationship between EW and surface type. By comparing Figure $2 a$ with $2 b$, it is evident for all EW that more ionomer adsorbs to alkane-thiol and platinum surfaces in $100 \%$ water than in 50:50 (wt\%) water: $n$ - 


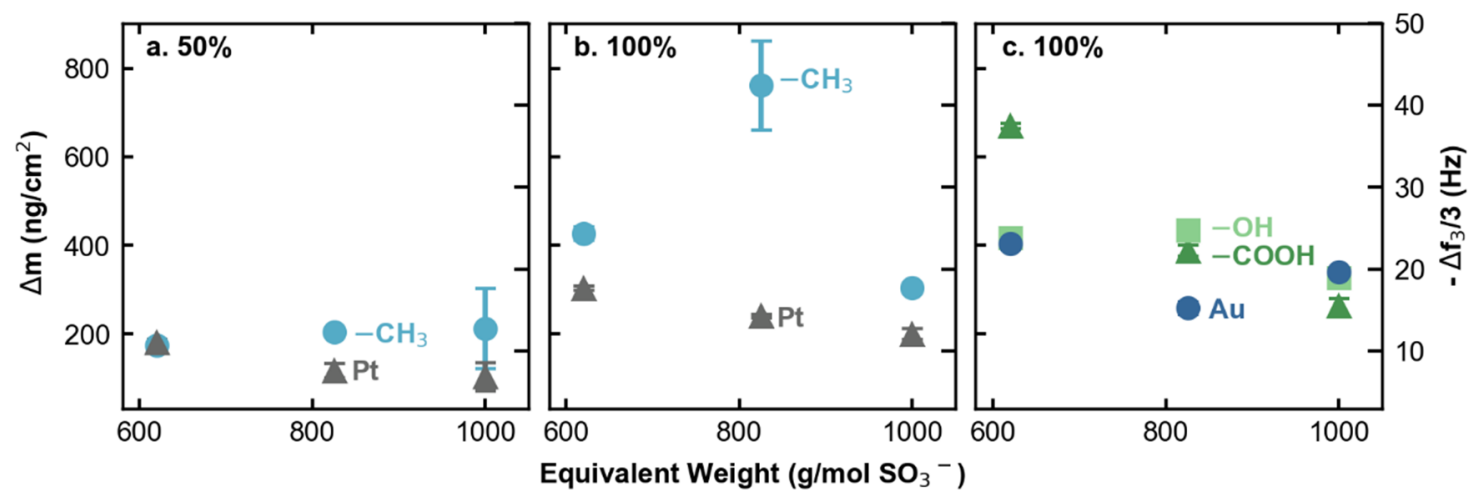

Figure 2. Frequency change $(\Delta \mathrm{f})$ measured at the third overtone and associated mass change $(\Delta \mathrm{m})$ due to ionomer adsorption in solution (as compared with pure solvent) for a range of EWs on surfaces with alkane $\left(-\mathrm{CH}_{3}\right)$, platinum ( $\left.\mathrm{Pt}\right)$, gold ( $\left.\mathrm{Au}\right)$, hydroxyl (-OH), and carboxyl (-COOH) functionality in (a.) 50:50 (wt\%) water:n-propanol and (b.,c.) 100\% water.

propanol (see Figure 1). In both solvent mixtures, as EW decreases, ionomer adsorption to platinum increases. This same trend is observed for the other hydrophilic surfaces studied in Figure 2c. Importantly, PFSA adsorption to platinum represents the lowest adsorption magnitude among the surfaces studied (in agreement with other studies that showed the PFSA/platinum interaction was weaker than the PFSA/gold interaction $\left.{ }^{35-36}\right)$. Some hypothesize that there is a strong specific interaction between PFSA sulfonate groups and platinum, and that this interaction drives PFSA adsorption to catalyst particles in inks. However, we do not see indications of this (due to low adsorption), counter to other experimental evidence that shows sulfonate adsorption to platinum surfaces ${ }^{35,37-39}$. This is rationalized because the platinum in those experiments was polarized (relative to the potential of zero charge ${ }^{40-43}$ ), while ours is under no applied potential. Additionally, in the operando PFSA/platinum interaction studies, the platinum is likely in a metallic state; conversely, the platinum surfaces here (and found in inks) will have some native oxide coverage, which has been shown to impact PFSA behavior. ${ }^{44}$ Therefore, the PFSA/platinum interaction in solution versus in operating CLs is different, likely due to different surface charge states. An explanation as to why PFSA adsorption increases with decreasing EW could be that as the ionomer becomes more hydrophilic (as shown by increased acidity ${ }^{13-}$ $\left.{ }^{14}\right)$, it can more readily interact with platinum; scattering studies show PFSA backbone chains orient on hydrophobic surfaces differently than they do on hydrophilic ones ${ }^{45-46}$. The PFSA/platinum interaction will be discussed further below.

Based on the platinum adsorption trend, one might expect the opposite trend for the hydrophobic surface: as ionomer EW increases, so would adsorption. This is seen weakly in the $50 \%$ solvent environment, but the trend very obviously deviates for $100 \%$ water. In the $50 \%$ solvent, the ionomer has a swollen, blob-like structure that is much looser than the collapsed structure at higher water contents. ${ }^{6,13-14}$ This swollen structure could result in high sidechain mobility, allowing for adsorption to scale with EW in a more linear manner than at higher water contents. With more collapsed conformations in pure water, ${ }^{5,13}$ it is reasonable to expect different trends. While additional solution structure data is needed to confirm this, it is possible that $3 \mathrm{M} 825$ possesses an appropriate ratio of hydrophilic and hydrophobic moieties such that its conformation in water is optimal for adsorption to hydrophobic surfaces; ITC data presented in the next section confirms that 3M 825 also possesses the strongest binding constant among the ionomers studied to hydrophobic surfaces. Indeed, this may be consistent with the fact that $3 \mathrm{M} 825$ is 3M's commercial dispersion for fuel cells. Additional reasons for the nonlinear EW trend could be due to differences in molecular weight ${ }^{47}$ between the ionomers.

Thermodynamics of Binding. To gain quantitative thermodynamic binding information and delineate the ionomer/particle interactions, ITC is performed with the various ionomers and platinum or Vulcan-carbon nanoparticles, where the latter is typically used in CLs and, as will be shown, is approximated by alkane-thiol SAMs in the QCM experiments. The ionomer dispersions are titrated into a sample cell containing nanoparticles (in pure water); the power required to keep the cell at a constant temperature is monitored. By integrating the power over time, adsorption heats and binding isotherms are measured. The data shown here are parameters (association constant, $\mathrm{K}_{\mathrm{A}}$, adsorption enthalpy and entropy) extracted from an independent (Langmuir) binding model fit with appropriate subtraction to remove heats of mixing/dilution (see SI for example raw data and model fits). Both freshly prepared dispersions (like those used in the QCM experiments) and aged dispersions (prepared two weeks prior and remixed before using) are studied.

Figure 3 shows $\mathrm{K}_{\mathrm{A}}$ for the three EWs on Vulcan carbon and platinum-black nanoparticles. Because the binding constants are on a gram basis, one should not compare values across different particle types (they will have a different number of binding sites per gram, molar data is presented in Figure S8). We first consider the new dispersion data. Notably, the EW trends on carbon and platinum are the same as those observed in the QCM experiments (Figure 2b): weaker binding is observed on platinum as EW increases, and binding to carbon has the same nonlinear EW dependence; the alkane-thiol surface is therefore a good proxy for 

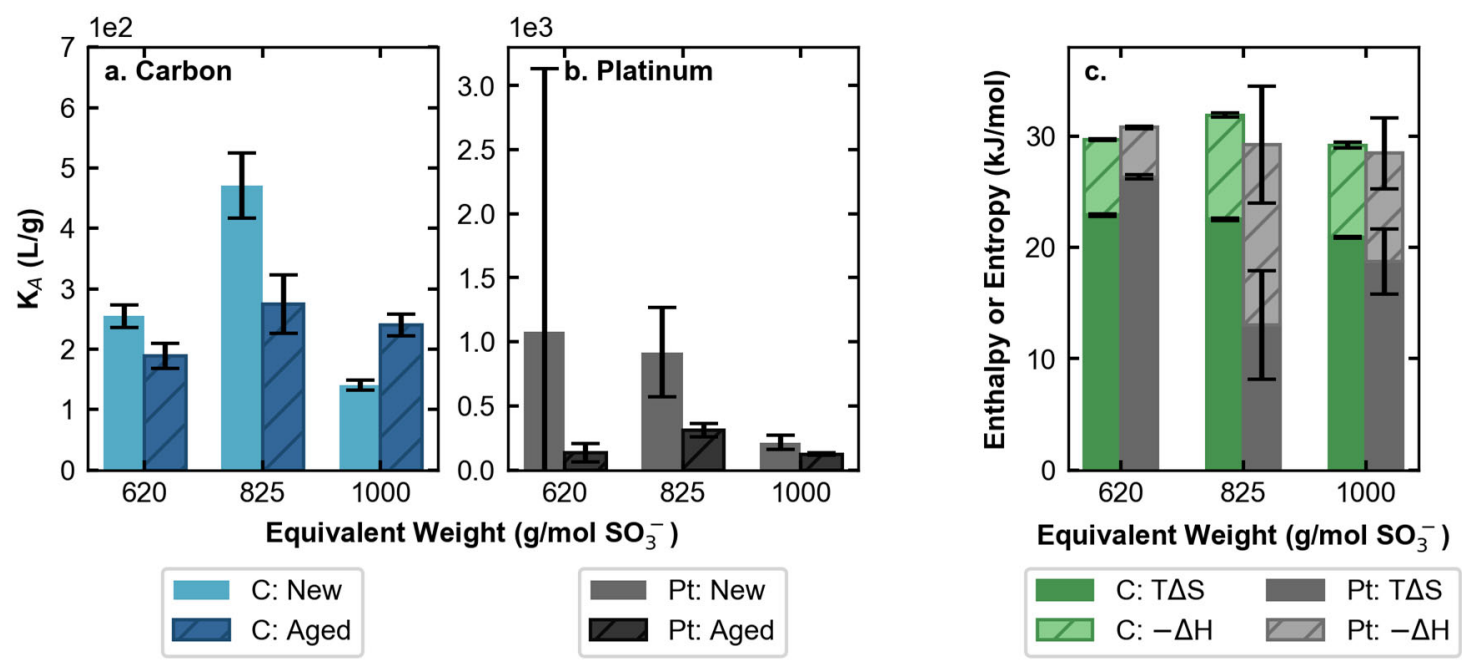

Figure 3. Association constants $\left(\mathrm{K}_{\mathrm{A}}\right)$ of ionomer binding to (a.) carbon or (b.) platinum nanoparticles for freshly prepared (New) or older (Aged) dispersions as a function of ionomer EW in water. Note quantitative comparisons should not be made between (a.) and (b.) because $K_{A}$ is on a gram basis. (c.) Stacked plot displaying the absolute value of the enthalpic and entropic contributions to the positive binding free energy for the New dispersions (all values indicate spontaneous adsorption).

Vulcan. The enthalpic $(-\Delta \mathrm{H})$ and entropic $(\mathrm{T} \Delta \mathrm{S})$ contribution to the positive free energy $\left(|\Delta G|=R T \ln \left[K_{A}\right]\right)$ for PFSA binding is plotted in Figure 3c. Energy values are in agreement with those calculated for other ionomer isotherms, ${ }^{48}$ and are similar or weaker than those observed for protein/surface interactions, ${ }^{49-51}$ although quantitative values depend on molar-conversion assumptions (see SI). Immediately evident is that the entropic contribution is larger than the enthalpic contribution, regardless of EW or particle identity. Enthalpic signatures are representative of specific-binding, hydrogen bonding, etc., while spontaneous entropicallydriven binding in aqueous solutions is often due to hydrophobic interactions. ${ }^{49,51}$ This data is consistent with previous $\mathrm{MD}^{17,21,23}$ and experimental ${ }^{52}$ results that conclude adsorption to carbon surfaces is driven by hydrophobic interactions with the backbone. Interestingly, PFSA adsorption to platinum is also entropically-dominated, suggesting specific-binding between sulfonate and platinum is not the primary ionomer/platinum interaction under these (non-polarized) conditions. This agrees with one study that noted the co-adsorption of fluorocarbon groups in addition to sulfonate at elevated potentials. ${ }^{35}$ These results indicate that the ionomer/platinum interaction is not especially strong (at least compared to the ionomer/carbon interaction) in inks, and that adsorption to platinum is controlled by a similar mechanism as to carbon.

Therefore, given the larger surface area of carbon relative to platinum in most electrocatalyst particles, PFSA/particle aggregation in inks is likely dominated by the PFSA/carbon interaction. Indeed, carbon treatment methods to tune the PFSA/carbon interaction have been successfully employed to control $\mathrm{CL}$ performance. ${ }^{53-54}$ Similarly, one metric often reported is the ionomer-to-carbon $(\mathrm{I} / \mathrm{C})$ ratio, where optimal ratios ${ }^{55-61}$ seem dependent on carbon type; given the results herein, ideal ratios will also likely vary with solvent and EW.
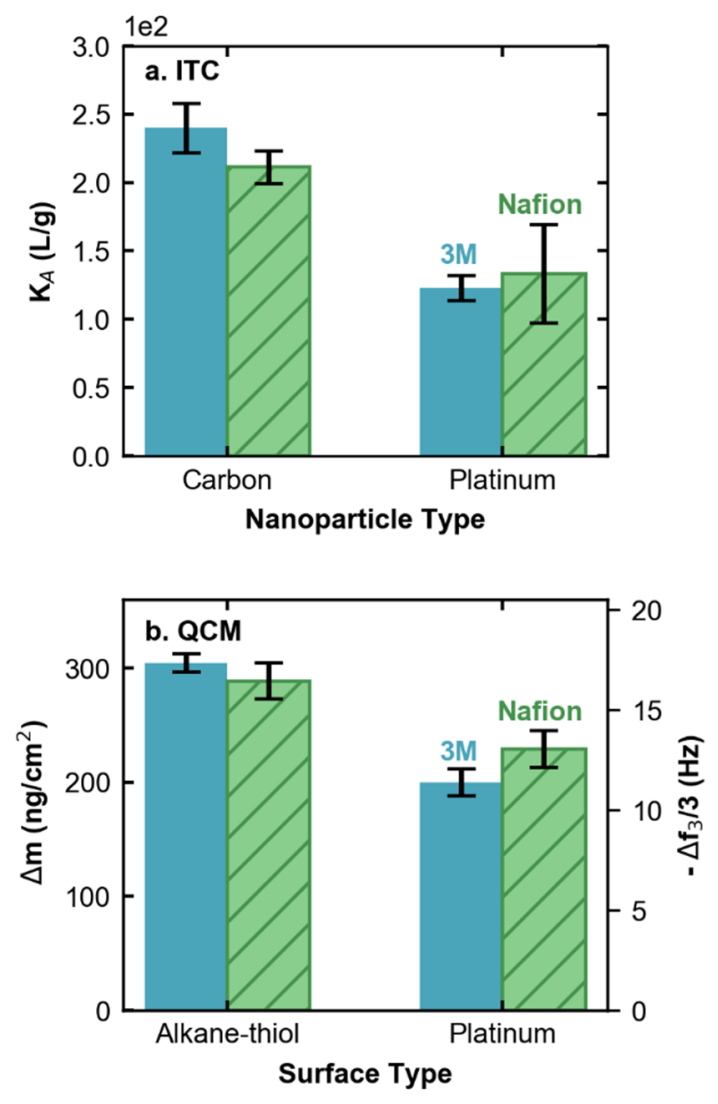

Figure 4. (a.) Association constants $\left(K_{A}\right)$ of $3 M 1000$ versus Nafion 1100 binding on carbon and platinum black nanoparticles from ITC measurements. (b.) Frequency change $(\Delta f)$ measured at the third overtone and associated mass change $(\Delta \mathrm{m})$ due to ionomer adsorption (3M 1000 or Nafion 1100) in 100\% water onto alkane-thiol-modified and platinum QCM surfaces.

Additional Parameters. Another consideration is how these PFSA/particle interactions vary with time. If the binding behavior of these dispersions is measured two weeks later, the interaction strength and trends change, as seen for the aged data in Figure 3. Generally, the interaction 
becomes weaker with time. However, the binding mechanism remains entropically driven (in fact, even more so, Figure S9). PFSA conformational changes are evidenced by the significant change in dispersion $\mathrm{pH}^{13}$ as a function of time (Figure S10). This suggests that there is a slow equilibrium timescale for reorganization when these dispersions are prepared, and that they maintain some memory of their previous state. This has critical implications for CLs cast from inks of different age, and may help explain changes in CL microstructure and performance. ${ }^{62}$

Finally, it is of interest to understand the role sidechain length and chemistry play on these interactions. To examine this, Figure 4 compares Nafion 1100 and 3M 1000 as they have same sidechain spacing but Nafion has a longer sidechain with an extra ether oxygen (see Figure S1). Within error, binding of these two ionomers to both particle types and adsorption to both QCM surfaces is the same. This indicates that EW is a stronger predictor of binding affinity than sidechain length, in agreement with model thin-film ${ }^{63}$ and $\mathrm{CL}$ studies. ${ }^{47}$

In summary, we used both QCM and ITC data to understand the influence of solvent environment, EW, surface type, and sidechain length on PFSA adsorption. As the water:propanol ratio increases, PFSA adsorption increases regardless of surface type, suggesting that hydrophobic partitioning drives adsorption. When holding solvent constant, adsorption strongly depends on EW and surface type. Interestingly, ITC data suggests the binding mechanism to platinum versus carbon is similar. Given this, and considering that adsorption is lower on platinum versus hydrophobic QCM surfaces, it is likely that ionomer/particle aggregation in inks is dominated by ionomer/carbon rather than ionomer/platinum interactions due to the larger carbon surface area relative to platinum in platinum-on-carbon nanoparticles. While additional work is needed to understand more completely how dispersions change with time, these ionomer/particle interactions are dynamic and have the potential to significantly influence ink aggregate structures (and eventual CL structures/interfaces). The complex surface/EW/solvent parameter space controls the forces between ink constituents and determines the CL microstructure upon drying; thus, the data presented herein is critical in unraveling the governing interactions and phenomena. More importantly, with this new understanding we can now engineer inks to promote (or demote) adsorption to specific surfaces in order to control optimal CL performance and electrode designs for many energy-conversion technologies.

\section{ASSOCIATED CONTENT}

\section{Supporting Information}

Details of experimental methods, including raw data and analysis for QCM and ITC, surface functionalization, adsorption kinetics, molar conversions, aging data $(\mathrm{pH}$, enthalpy/entropy)

\section{AUTHOR INFORMATION}

\section{Corresponding Author}

*Adam Z. Weber: azweber@lbl.gov

\section{ACKNOWLEDGMENT}

The authors would like to thank Dr. Behzad Rad, Professor Clayton Radke, Dr. Andrew Crothers, Ms. Rebecca Pinals, and Dr. Peter Dudenas for helpful discussions. This material is primarily based on work performed by the Million Mile Fuel Cell Truck ( $\mathrm{M}^{2} \mathrm{FCT}$ ) Consortium (https://millionmilefuelcelltruck.org), technology manager Greg Kleen, which is supported by the U.S. Department of Energy, Office of Energy Efficiency and Renewable Energy, Hydrogen and Fuel Cell Technologies Office, under contract number DE-ACO205CH1123, with initial funding from the Fuel Cell Performance and Durability Consortium (FC-PAD). ITC work conducted at the Molecular Foundry was supported by the Office of Science, Office of Basic Energy Sciences, of the U.S. Department of Energy under Contract No. DE-ACO205CH11231. S.A.B acknowledges support from the Graduate Research Fellowship Program by the National Science Foundation under Grant No. DGE 1752814.

\section{REFERENCES}

1. Holdcroft, S., Fuel Cell Catalyst Layers: A Polymer Science Perspective. Chem. Mater. 2014, 26 (1), 381-393.

2. Hatzell, K. B.; Dixit, M. B.; Berlinger, S. A.; Weber, A. Z., Understanding inks for porous-electrode formation. J. Mater. Chem. A 2017, 5 (39), 20527-20533.

3. Kusoglu, A.; Weber, A. Z., New Insights into Perfluorinated Sulfonic-Acid lonomers. Chem. Rev. 2017, 117 (3), 987-1104.

4. Woo, S.; Lee, S.; Taning, A. Z.; Yang, T.-H.; Park, S.-H.; Yim, S.D., Current understanding of catalyst/ionomer interfacial structure and phenomena affecting the oxygen reduction reaction in cathode catalyst layers of proton exchange membrane fuel cells. Current Opinion in Electrochemistry 2020.

5. Gebel, G.; Loppinet, B., Colloidal structure of ionomer solutions in polar solvents. J. Mol. Struct. 1996, 383 (1), 4349.

6. Welch, C.; Labouriau, A.; Hjelm, R.; Orler, B.; Johnston, C.; Kim, Y. S., Nafion in Dilute Solvent Systems: Dispersion or Solution? ACS Macro. Lett. 2012, 1 (12), 1403-1407.

7. Lee, S.-J.; Yu, T. L.; Lin, H.-L.; Liu, W.-H.; Lai, C.-L., Solution properties of nafion in methanol/water mixture solvent. Polymer 2004, 45 (8), 2853-2862.

8. Aldebert, P.; Gebel, G.; Loppinet, B.; Nakamura, N., Polyelectrolyte effect in perfluorosulfonated ionomer solutions. Polymer 1995, 36 (2), 431-434.

9. Loppinet, B.; Gebel, G.; Williams, C. E., Small-Angle Scattering Study of Perfluorosulfonated lonomer Solutions. J. Phys. Chem. B. 1997, 101 (10), 1884-1892.

10. Loppinet, B.; Gebel, G., Rodlike Colloidal Structure of Short Pendant Chain Perfluorinated Ionomer Solutions. Langmuir 1998, 14 (8), 1977-1983.

11. Mabuchi, T.; Huang, S.-F.; Tokumasu, T., Nafion Ionomer Dispersion in Mixtures of 1-Propanol and Water Based on the Martini Coarse-Grained Model. Journal of Polymer Science 2020, 58 (3), 487-499. 
12. Mabuchi, T.; Huang, S.-F.; Tokumasu, T., Dispersion of Nafion Ionomer Aggregates in 1-Propanol/Water Solutions: Effects of Ionomer Concentration, Alcohol Content, and Salt Addition. Macromolecules 2020, 53 (9), 3273-3283.

13. Berlinger, S. A.; McCloskey, B. D.; Weber, A. Z., Inherent Acidity of Perfluorosulfonic Acid lonomer Dispersions and Implications for Ink Aggregation. J. Phys. Chem. B. 2018, 122 (31), 7790-7796.

14. Tarokh, A.; Karan, K.; Ponnurangam, S., Atomistic MD Study of Nafion Dispersions: Role of Solvent and Counterion in the Aggregate Structure, Ionic Clustering, and Acid Dissociation. Macromolecules 2020, 53 (1), 288-301.

15. Berlinger, S. A.; Dudenas, P. J.; Bird, A.; Chen, X.; Freychet, G.; McCloskey, B. D.; Kusoglu, A.; Weber, A. Z., Impact of Dispersion Solvent on lonomer Thin Films and Membranes. ACS Applied Polymer Materials 2020, 2 (12), 5824-5834.

16. Dudenas, P. J.; Kusoglu, A., Evolution of lonomer Morphology from Dispersion to Film: An in Situ X-ray Study. Macromolecules 2019, 52 (20), 7779-7785.

17. Mashio, T.; Ohma, A.; Tokumasu, T., Molecular Dynamics Study of Ionomer Adsorption at a Carbon Surface in Catalyst Ink. Electrochim. Acta 2016, 202, 14-23.

18. Dixit, M. B.; Harkey, B. A.; Shen, F.; Hatzell, K. B., Catalyst Layer Ink Interactions That Affect Coatability. J. Electrochem. Soc. 2018, 165 (5), F264-F271.

19. Shukla, S.; Bhattacharjee, S.; Weber, A. Z.; Secanell, M., Experimental and Theoretical Analysis of Ink Dispersion Stability for Polymer Electrolyte Fuel Cell Applications. J. Electrochem. Soc. 2017, 164 (6), F600-F609.

20. Orfanidi, A.; Rheinländer, P. J.; Schulte, N.; Gasteiger, H. A., Ink Solvent Dependence of the lonomer Distribution in the Catalyst Layer of a PEMFC. J. Electrochem. Soc. 2018, 165 (14), F1254-F1263.

21. Malek, K.; Eikerling, M.; Wang, Q.; Navessin, T.; Liu, Z., SelfOrganization in Catalyst Layers of Polymer Electrolyte Fuel Cells. J. Phys. Chem. C. 2007, 111 (36), 13627-13634.

22. Khandavalli, S.; Park, J. H.; Kariuki, N. N.; Myers, D. J.; Stickel, J. J.; Hurst, K.; Neyerlin, K. C.; Ulsh, M.; Mauger, S. A., Rheological Investigation on the Microstructure of Fuel Cell Catalyst Inks. ACS Appl. Mater. Interfaces 2018, 10 (50), 43610-43622.

23. Mashio, T.; Malek, K.; Eikerling, M.; Ohma, A.; Kanesaka, H.; Shinohara, K., Molecular Dynamics Study of Ionomer and Water Adsorption at Carbon Support Materials. J. Phys. Chem. C. 2010, 114 (32), 13739-13745.

24. Shin, S. J.; Lee, J. K.; Ha, H. Y.; Hong, S. A.; Chun, H. S.; Oh, I. $\mathrm{H}$. , Effect of the catalytic ink preparation method on the performance of polymer electrolyte membrane fuel cells. J. Power Sources 2002, 106 (1-2), 146-152.

25. Xie, Z.; Navessin, T.; Zhao, X.; Adachi, M.; Holdcroft, S.; Mashio, T.; Ohma, A.; Shinohara, K., Nafion lonomer Aggregation and its Influence on Proton Conduction and Mass Transport in Fuel Cell Catalyst Layers. ECS Trans. 2008, 16 (2), 1811-1816.

26. Ngo, T. T.; Yu, T. L.; Lin, H.-L., Influence of the composition of isopropyl alcohol/water mixture solvents in catalyst ink solutions on proton exchange membrane fuel cell performance. J. Power Sources 2013, 225, 293-303.

27. Uchida, M.; Aoyama, Y.; Eda, N.; Ohta, A., New Preparation Method for Polymer-Electrolyte Fuel Cells. J. Electrochem. Soc. 1995, 142 (2), 463-468.

28. Huang, D. C.; Yu, P. J.; Liu, F. J.; Huang, S. L.; Hsueh, K. L.; Chen, Y. C.; Wu, C. H.; Chang, W. C.; Tsau, F. H., Effect of Dispersion Solvent in Catalyst Ink on Proton Exchange Membrane Fuel
Cell Performance. Int. J. Electrochem. Sci. 2011, 6 (7), 25512565.

29. Johnston, C. M.; Lee, K.-S.; Rockward, T.; Labouriau, A.; Mack, N.; Kim, Y. S., Impact of Solvent on lonomer Structure and Fuel Cell Durability. ECS Trans. 2009, 25 (1), 1617-1622.

30. Therdthianwong, A.; Ekdharmasuit, P.; Therdthianwong, S., Fabrication and Performance of Membrane Electrode Assembly Prepared by a Catalyst-Coated Membrane Method: Effect of Solvents Used in a Catalyst Ink Mixture. Energy Fuels 2010, 24 (2), 1191-1196.

31. Kim, T.-H.; Yi, J.-Y.; Jung, C.-Y.; Jeong, E.; Yi, S.-C., Solvent effect on the Nafion agglomerate morphology in the catalyst layer of the proton exchange membrane fuel cells. Int. J. Hydrogen Energy 2017, 42 (1), 478-485.

32. Van Cleve, T.; Khandavalli, S.; Chowdhury, A.; Medina, S.; Pylypenko, S.; Wang, M.; More, K. L.; Kariuki, N.; Myers, D. J.; Weber, A. Z.; Mauger, S. A.; Ulsh, M.; Neyerlin, K. C., Dictating Pt-Based Electrocatalyst Performance in Polymer Electrolyte Fuel Cells, from Formulation to Application. ACS Appl. Mater. Interfaces 2019, 11 (50), 46953-46964.

33. Devivaraprasad, R.; Masuda, T., Solvent-Dependent Adsorption of Perfluorosulfonated lonomers on a Pt(111) Surface Using Atomic Force Microscopy. Langmuir 2020, 36 (46), 13793-13798.

34. Van Cleve, T.; Wang, G.; Mooney, M.; Cetinbas, C. F.; Kariuki, N.; Park, J.; Farghaly, A.; Myers, D.; Neyerlin, K. C., Tailoring electrode microstructure via ink content to enable improved rated power performance for platinum cobalt/high surface area carbon based polymer electrolyte fuel cells. J. Power Sources 2021, 482, 228889.

35. Masuda, T.; Sonsudin, F.; Singh, P. R.; Naohara, H.; Uosaki, K., Potential-Dependent Adsorption and Desorption of Perfluorosulfonated Ionomer on a Platinum Electrode Surface Probed by Electrochemical Quartz Crystal Microbalance and Atomic Force Microscopy. J. Phys. Chem. C. 2013, 117 (30), 15704-15709.

36. Masuda, T.; Ikeda, K.; Uosaki, K., Potential-Dependent Adsorption/Desorption Behavior of Perfluorosulfonated Ionomer on a Gold Electrode Surface Studied by Cyclic Voltammetry, Electrochemical Quartz Microbalance, and Electrochemical Atomic Force Microscopy. Langmuir 2013, 29 (7), 2420-2426.

37. Subbaraman, R.; Strmcnik, D.; Stamenkovic, V.; Markovic, N. M., Three Phase Interfaces at Electrified Metal-Solid Electrolyte Systems 1. Study of the Pt(hkl)-Nafion Interface. J. Phys. Chem. C. 2010, 114 (18), 8414-8422.

38. Kendrick, I.; Kumari, D.; Yakaboski, A.; Dimakis, N.; Smotkin, E. S., Elucidating the Ionomer-Electrified Metal Interface. Journal of the American Chemical Society 2010, 132 (49), 17611-17616.

39. Koestner, R.; Roiter, Y.; Kozhinova, I.; Minko, S., Effect of Local Charge Distribution on Graphite Surface on Nafion Polymer Adsorption as Visualized at the Molecular Level. J. Phys. Chem. C. 2011, 115 (32), 16019-16026.

40. Muzaffar, T.; Kadyk, T.; Eikerling, M., Physical Modeling of the Proton Density in Nanopores of PEM Fuel Cell Catalyst Layers. Electrochim. Acta 2017, 245, 1048-1058.

41. Garrick, T. R.; Moylan, T. E.; Yarlagadda, V.; Kongkanand, A., Characterizing Electrolyte and Platinum Interface in PEM Fuel Cells Using CO Displacement. J. Electrochem. Soc. 2016, 164 (2), F60-F64.

42. Huang, J.; Malek, A.; Zhang, J.; Eikerling, M. H., Nonmonotonic Surface Charging Behavior of Platinum: A 
Paradigm Change. J. Phys. Chem. C. 2016, 120 (25), 1358713595.

43. Zenyuk, I. V.; Litster, S., Modeling ion conduction and electrochemical reactions in water films on thin-film metal electrodes with application to low temperature fuel cells. Electrochim. Acta 2014, 146, 194-206.

44. Tesfaye, M.; MacDonald, A. N.; Dudenas, P. J.; Kusoglu, A.; Weber, A. Z., Exploring substrate/ionomer interaction under oxidizing and reducing environments. Electrochemistry Communications 2018, 87, 86-90.

45. Modestino, M. A.; Kusoglu, A.; Hexemer, A.; Weber, A. Z.; Segalman, R. A., Controlling Nafion Structure and Properties via Wetting Interactions. Macromolecules 2012, 45 (11), 4681-4688.

46. Karan, K., Interesting Facets of Surface, Interfacial, and Bulk Characteristics of Perfluorinated Ionomer Films. Langmuir 2019, 35 (42), 13489-13520.

47. Nagappan, R.; Swami, K.; Roland, K.; Timothy, F.; Wenbin, G.; Nancy, N. K.; Deborah, J. M.; Peter, J. D.; Ahmet, K., Editors' Choice-lonomer Side Chain Length and Equivalent Weight Impact on High Current Density Transport Resistances in PEMFC Cathodes. J. Electrochem. Soc. 2021.

48. Thoma, M.; Lin, W.; Hoffmann, E.; Sattes, M.; Segets, D.; Damm, C.; Peukert, W., A simple and reliable method for studying the adsorption behavior of Aquivion ${ }^{\circledR}$ ionomers on carbon black surfaces. Langmuir 2018.

49. Norde, W., ENERGY AND ENTROPY OF PROTEIN ADSORPTION. Journal of Dispersion Science and Technology 1992, 13 (4), 363-377.

50. Johnson, R. D.; Arnold, F. H., The temkin isotherm describes heterogeneous protein adsorption. Biochimica et Biophysica Acta (BBA) - Protein Structure and Molecular Enzymology 1995, 1247 (2), 293-297.

51. Prozeller, D.; Morsbach, S.; Landfester, K., Isothermal titration calorimetry as a complementary method for investigating nanoparticle-protein interactions. Nanoscale 2019, 11 (41), 19265-19273.

52. Takuya, M.; Hideo, N.; Satoru, T.; R., S. P.; Kohei, U., Formation and Structure of Perfluorosulfonated Ionomer Thin Film on a Graphite Surface. Chem. Lett. 2009, 38 (9), $884-$ 885.

53. Pramounmat, N.; Loney, C. N.; Kim, C.; Wiles, L.; Ayers, K. E.; Kusoglu, A.; Renner, J. N., Controlling the Distribution of
Perfluorinated Sulfonic Acid Ionomer with Elastin-like Polypeptide. ACS Appl. Mater. Interfaces 2019.

54. Orfanidi, A.; Madkikar, P.; El-Sayed, H. A.; Harzer, G. S.; Kratky, T.; Gasteiger, H. A., The Key to High Performance Low Pt Loaded Electrodes. J. Electrochem. Soc. 2017, 164 (4), F418-F426.

55. Passalacqua, E.; Lufrano, F.; Squadrito, G.; Patti, A.; Giorgi, L., Nafion content in the catalyst layer of polymer electrolyte fuel cells: effects on structure and performance. Electrochim. Acta 2001, 46 (6), 799-805.

56. Antolini, E.; Giorgi, L.; Pozio, A.; Passalacqua, E., Influence of Nafion loading in the catalyst layer of gas-diffusion electrodes for PEFC. J. Power Sources 1999, 77 (2), 136-142.

57. Sasikumar, G.; Ihm, J. W.; Ryu, H., Optimum Nafion content in PEM fuel cell electrodes. Electrochim. Acta 2004, 50 (2-3), 601-605.

58. Zhao, X.; Li, W.; Fu, Y.; Manthiram, A., Influence of ionomer content on the proton conduction and oxygen transport in the carbon-supported catalyst layers in DMFC. Int. J. Hydrogen Energy 2012, 37 (12), 9845-9852.

59. Ishikawa, H.; Sugawara, Y.; Inoue, G.; Kawase, M., Effects of Pt and ionomer ratios on the structure of catalyst layer: $A$ theoretical model for polymer electrolyte fuel cells. J. Power Sources 2018, 374, 196-204.

60. Alink, R.; Singh, R.; Schneider, P.; Christmann, K.; Schall, J.; Keding, R.; Zamel, N., Full Parametric Study of the Influence of lonomer Content, Catalyst Loading and Catalyst Type on Oxygen and Ion Transport in PEM Fuel Cell Catalyst Layers. Molecules 2020, 25 (7), 1523.

61. Schuler, T.; Chowdhury, A.; Freiberg, A. T.; Sneed, B.; Spingler, F. B.; Tucker, M. C.; More, K. L.; Radke, C. J.; Weber, A. Z., Fuel-Cell Catalyst-Layer Resistance via Hydrogen LimitingCurrent Measurements. J. Electrochem. Soc. 2019, 166 (7), F3020-F3031.

62. Uemura, S.; Yoshida, T.; Koga, M.; Matsumoto, H.; Yang, X.; Shinohara, K.; Sasabe, T.; Hirai, S., Ink Degradation and Its Effects on the Crack Formation of Fuel Cell Catalyst Layers. J. Electrochem. Soc. 2019, 166 (2), F89-F92.

63. Kusoglu, A.; Dursch, T. J.; Weber, A. Z., Nanostructure/Swelling Relationships of Bulk and Thin-Film PFSA Ionomers. Advanced Functional Materials 2016, 26 (27), 4961-4975. 